\title{
Development and psychometric properties of a five-language multiperspective instrument to assess clinical decision making style in the treatment of people with severe mental illness (CDMS)
}

Bernd Puschner ${ }^{1 *}$, Petra Neumann ${ }^{1}$, Harriet Jordan², Mike Slade ${ }^{2}$, Andrea Fiorillo $^{3}$, Domenico Giacco ${ }^{3}$, Anikó Égerházi ${ }^{4}$, Tibor Ivánka ${ }^{4}$, Malene Krogsgaard Bording ${ }^{5}$, Helle Østermark Sørensen ${ }^{5}$, Arlette Bär ${ }^{6}$, Wolfram Kawohl ${ }^{6}$ and Sabine Loos ${ }^{1}$, for the CEDAR study group

\begin{abstract}
Background: The aim of this study was to develop and evaluate psychometric properties of the Clinical Decision Making Style (CDMS) scale which measures general preferences for decision making as well as preferences regarding the provision of information to the patient from the perspectives of people with severe mental illness and staff.

Methods: A participatory approach was chosen for instrument development which followed 10 sequential steps proposed in a current guideline of good practice for the translation and cultural adaptation of measures. Following item analysis, reliability, validity, and long-term stability of the CDMS were examined using Spearman correlations in a sample of 588 people with severe mental illness and 213 mental health professionals in 6 European countries (Germany, UK, Italy, Denmark, Hungary, and Switzerland).

Results: In both patient and staff versions, the two CDMS subscales "Participation in Decision Making" and "Information" reliably measure distinct characteristics of decision making. Validity could be demonstrated to some extent, but needs further investigation.

Conclusions: Together with two other five-language patient- and staff-rated measures developed in the CEDAR study (ISRCTN75841675) - "Clinical Decision Making in Routine Care" and "Clinical Decision Making Involvement and Satisfaction" - the CDMS allows empirical investigation of the complex relation between clinical decision making and outcome in the treatment of people with severe mental illness across Europe.
\end{abstract}

\section{Background}

Decision-making in health care has been conceptualized as a process taking place between patient and health professional on a continuum between "paternalistic", "shared", and "informed" [1,2]. Shared decision making has received much attention in research and practice since its first mention 30 years ago [3]. Substantial

\footnotetext{
* Correspondence: bernd.puschner@bkh-guenzburg.de

'Department of Psychiatry II, Ulm University, Ludwig-Heilmeyer-Str. 2,

Günzburg 89312, Germany

Full list of author information is available at the end of the article
}

evidence has accumulated in recent decades for clinical decision making in acute (e.g. heart attack, stroke) and long-term physical conditions (e.g. cancer and fibromyalgia) [4-10]. Shared decision making has been termed an ethical imperative [11] and is recommended in guidelines for the treatment of people with schizophrenia [12].

However, knowledge about clinical decision making in the treatment of people with mental illness is still limited. Most importantly, apart from a few studies [13], little is known about the relation between clinical decision

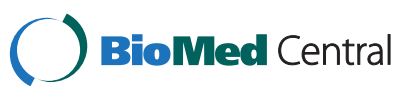


making processes and outcome in this population. Knowledge gaps relating to investigating this link have been identified, including: (a) descriptive research and instrument development focussing on how decisions are actually made in routine care; (b) the development of measures to characterize decision making processes, especially in people with long-term mental disorder; and (c) the measurement of both patients' and professionals' decision making styles and how these are enacted in decision making encounters [14-16].

Published scales measuring decision making have been summarised in four recent reviews; three with a focus on shared decision making [16-19] and one specifically examining professionals' perceptions of decision making [20]. Scales identified in these reviews measured a wide range of aspects of clinical decision making, which were thematically grouped by the authors of these reviews: "decision making needs", "decision support", and "evaluation of process and outcome" by Simon and colleagues [17]; "values and preferences", "information and communication", and "other" by Dy [18]; and "antecedents", "process" and "outcomes" by Scholl and colleagues [19].

However, psychometric properties of most measures, especially validity, have not yet been sufficiently demonstrated $[17,19]$. Furthermore, many instruments assess preferences at a high level of abstraction, while little is known about actual decision behaviour in routine care [18]. Moreover, by exclusively assessing decision making from the perspective of the patient, instrument development has largely ignored reciprocity as a defining feature of decision making [1,21-23]. For example, even though some instruments to assess decision making from the perspective of health professionals have been developed [20], there is a lack of parallel versions with an explicit focus on the reciprocal assessment of decision making $[17,19]$ from both patient and professional perspectives.

With a few exceptions (e.g. [24]), instruments used to assess decision making in the treatment of people with mental illness have been developed in samples of people with physical conditions (mainly cancer). However, there is emerging evidence that psychometric properties of decision making measures substantially vary by illness and treatment variables [25]. Thus, untested use of an instrument in populations other than the original target sample may be problematic. Nevertheless, some scales developed for other conditions have been successfully validated for assessing decision making in the treatment of people with mental illness, e.g. [26,27]. Notably the "Autonomy Preference Index" (API) [28] consisting of two subscales (15 item "decision-making preferences" and 8-item "information-seeking preferences") has been widely used in mental health research [29-31]. Internal consistency (Cronbach's $\alpha$ ) of the original version [28] examined in 312 general medicine patients was .82 for both subscales, and test-retest reliability after two weeks in a subsample $(\mathrm{N}=50)$ was .84 for the decision making preferences subscale, and .83 for the information seeking preferences subscale. For an abridged version of the API decision-making preferences subscale (6 items), a German study reported internal consistencies (Cronbach's $\alpha$ ) of .79 for GP patients with depression $(\mathrm{N}=230)$, and of .59 for psychiatric inpatients with schizophrenia $(\mathrm{N}=120)$ [32]. In a confirmatory factor analysis, three items showed questionable reliability in a sample of 1,592 patients with various conditions including 186 people with depression [33].

In order to measure key aspects of clinical decision making in the routine care for people with severe mental illness, the CEDAR study developed patient and staff versions of three new instruments, to measure: clinical decision making style; key elements of clinical decision making in routine care; and clinical decision making involvement and satisfaction.

This paper reports on the development and translation of the Clinical Decision Making Style Scale (CDMS), and investigates its psychometric properties (internal consistency, validity, and test-retest reliability) in a sample of 588 people with severe mental illness and 213 mental health professionals from six European countries. The development and psychometric properties of the Clinical Decision Making Involvement and Satisfaction Scale (CDIS) and the Clinical Decision Making in Routine Care Scale (CDRC) are reported elsewhere [34,35].

\section{Methods}

\section{Instrument development}

Development of the Clinical Decision Making Style Scale (CDMS) followed the International Society for Pharmacoeconomics and Outcomes Research (ISPOR) Task Force principles of good practice for the translation and cultural adaptation of patient-reported outcome measures [36]. The ISPOR Framework identifies ten sequential steps: 1 preparation; 2 forward translation; 3 reconciliation; 4 back translation; 5 back translation review; 6 harmonisation; 7 cognitive debriefing; 8 review of cognitive debriefing results and finalisation; 9 proof-reading; and 10 final report. We refer to these steps as ISPOR 1 to ISPOR 10 respectively.

Focus groups were held in ISPOR 1 and 7. Focus groups are widely used to examine people's experience with illness and health services. They especially aim at enabling vulnerable people to freely express their views in the format of a moderated group discussion [37-39]. Patient participants of focus groups were convenience samples of native speaker adults aged 18-60 using local non-forensic mental health services. Staff participants were workers in these services. Focus groups were held in non-clinical settings, and moderated and co- 
facilitated by two CEDAR research workers who ensured that all responders had sufficient opportunity to air their views and that non-verbal group dynamics were noted. All focus groups were audiotaped and fully transcribed.

\section{Development of the source language CDMS (ISPOR 1)}

At the first CEDAR study meeting in May 2009, Ulm research workers presented results of an extensive literature search on the instruments with a special focus on identifying scales to be considered candidates for inclusion. Presentations were discussed by the study group including advisory board member, which informed the drafting of a topic guide for the first round of focus groups. Subsequently, six focus groups (4 with 23 patients altogether, 2 with 8 clinicians altogether) were held by researchers in Ulm to explore the conceptual understanding of clinical decision-making. Topics covered included the experience of making decisions as well as level of involvement and satisfaction with the process during the last treatment session. Procedures and results of these focus groups have been reported in detail elsewhere [40]. Subsequently the patient-rated "Autonomy Preference Index" (API) [28] was chosen as the basis of the CDMS, from which the Ulm study team produced a parallel staff version. Both versions were in English. Permission to use the instrument was granted by the author of the API (J. Ende).

\section{Development of the target language CDMS (ISPOR 2-10)}

The API was forward translated from English into the four other study languages (German, Italian, Hungarian, and Danish; Switzerland used the German version) (ISPOR 2). Forward translations in each centre were done by native speakers of the target language who were familiar with the concepts of the instrument. Assistance from professional translators was drawn upon as needed, and where more than one forward translations was produced independently of one another at a study centre, these were compared and merged into one single forward translation (ISPOR 3). Subsequently, in each study centre one person fluent in the source language who had not been involved into the forward translation(s) carried out a blind (without seeing the source) back translation into the source language (ISPOR 4). Back translations were then compared to the original by CEDAR team members who were English native speakers (ISPOR 5), and potential discrepancies were discussed with the key in-country person and corrected as needed (ISPOR 6). Patient and staff versions of instrument drafts were then subjected to a total of 17 focus groups (9 with 33 patients altogether, and 8 with 31 key workers altogether) at all study sites in order to test alternative wording and to check understandability, interpretation, feasibility, and cultural relevance of the translations
(ISPOR 7). Review of cognitive debriefing results based upon reports of previous step to the Ulm study centre resulted in some final amendments including changes in text and omission of some items in order to arrive at short and understandable measures. These changes were: (i) omission of three items relating to informationseeking ("You should understand completely what is happening inside your body as a result of your illness"; "Even if the news is bad, you should be well informed"; "Information about your illness is as important to you as treatment"); (ii) some changes in wording (e.g. "clinician" instead of "doctor", "I" instead of "you"); (iii) replacement of the content of the three clinical vignettes which in the original API relate to physical conditions (upper respiratory tract illness, hypertension, and myocardial infarction) by vignettes relevant to people with mental illness (work, side effects, and medication); and (iv) to achieve conceptual equivalence and logical consistency between the parallel patient and staff versions, staff version wording of items scores in section B and item content was adapted (ISPOR 8). Final versions were then carefully proofread by local CEDAR team members and checked for consistency in order of items and format by the Ulm study team (ISPOR 9). This paper comprises the final report of the entire process of instrument development (ISPOR 10).

\section{Psychometric evaluation}

Following its development, the reliability and validity of the CDMS was examined using data from the study "Clinical Decision Making and Outcome in Routine Care for People with Severe Mental Illness" (CEDAR; ISRCTN75841675). Between November 2009 and December 2010, 588 people with severe mental illness gave informed consent to participate in the CEDAR study which is a naturalistic prospective longitudinal observational study with bimonthly assessments during a 12month observation period (T0-T6). Participants were recruited from the caseloads of outpatient/community mental health services at six centres throughout Europe: Department of Psychiatry II, Ulm University, Germany (coordinating centre); South London and Maudsley NHS Foundation Trust, London, U.K.; the Department of Psychiatry at Second University of Naples, Italy; the Department of Psychiatry at Debrecen University, Hungary; the Unit for Psychiatric Research at Aalborg Psychiatric Hospital, Denmark; and the Department of General and Social Psychiatry at University of Zurich, Switzerland. Before the start of recruitment, the study protocol was approved by ethics committees in all centres: Ulm University Ethics Commission; Joint South London and Maudsley and Institute of Psychiatry Research Ethics Committee; Ethical Committee of the Second University of Naples, Naples; National Committee on Health 
Research Ethics, North Denmark Region; Regional and Institutional Ethics Committee, University of Debrecen Medical and Health Science Center; and Kantonale Ethikkommission Zürich. Inclusion criteria were: adult age (18-60 years) at intake, mental disorder of any kind as main diagnosis established by case notes or staff communication using SCID criteria [41,42], presence of severe mental illness (Threshold Assessment Grid [43] $\geq 5$ points and illness duration $\geq 2$ years); expected contact with mental health services (excluding inpatient services) during the time of study participation; sufficient command of the host country's language; and capability of giving informed consent. Exclusion criteria were: main diagnosis of learning disability, dementia, substance use or organic brain disorder; cognitive impairment severe enough to make it impossible to give meaningful information on study measures; and treatment by forensic mental health services. Staff were recruited via patients who identified a key professional at baseline. Data were collected using questionnaires (filled in by the patient or his or her key worker) or through interviews conducted by the CEDAR research workers. Data entry modes were via computer or paper-pencil forms. See Puschner et al. [16] for further details on rationale and design of the CEDAR study.

\section{Measures}

The CDMS is a modified version of the "Autonomy Preference Index" [28] adapted for use in mental health care (see above). Patient (CDMS-P) and staff (CDMS-S) versions both have 21 items in three sections: (A) 6 items referring to general preferences regarding patient autonomy in decisions (items $\# 1, \# 2, \# 3$ and $\# 5$ are reversed); (B) 9 items referring to decision making preferences in three scenarios (3 per vignette); and (C) 6 items referring to desire for information (item \#19 is reversed). Items in sections $\mathrm{A}$ and $\mathrm{C}$ are each rated on a five-point Likert scale from "strongly disagree" (0) to "strongly agree" (4). Items in section B are scored from 4 ("Me") to 0 ("Clinician") in CDMS-P, and from 4 ("Service user") to 0 ("Me") in CDMS-S.

CDMS subscales are Participation in Decision Making (PD) which consists of the prorated mean of items in sections $\mathrm{A}$ and $\mathrm{B}$ (ranging 0-4, with a higher score indicating a higher desire by the service user to be an active participant in decision making), and Information (IN) consisting of the prorated mean of items in sections $\mathrm{C}$ (ranging 0-4, 0 with a higher score indicating a higher desire by the service user to be provided with information). CDMS total scores were prorated when at least $80 \%$ of the items making up a scale had been completed, i.e. at least 12 items of the PD subscale, and at least 4 items of the IN subscale. Categorical sum scores were formulated on the basis of utility where an emphasis was placed on separating categories according to clinical meaningfulness. Categories for PD subscale were Passive $(<1.5)$, Shared (1.5-2.5) and Active $(>2.5)$, and for IN subscale were Low $(<2.0)$, Moderate (2.0-3.0) and High (>3.0). These categories distinguish groups by their ordinal nature but not by a specific value assigned to each category. The CDMS patient and staff versions in all five CEDAR study languages can be downloaded at www. cedar-net.eu/instruments.

Two items from the "Clinical Decision Making Involvement and Satisfaction" scale (CDIS, [34]), comprising level of involvement (five point scale from "I made the final decision" through "My clinician and I shared responsibility for making the best decision for me" to "My clinician made the final decision") and satisfaction ("I am satisfied that I am adequately informed about the issues important to the decision"; five point scale from "strongly disagree" to "strongly agree").

The Stages of Recovery Inventory (STORI) is a patientrated 30-item assessment resulting in allocation to one of three stages of recovery ("Moratorium", "Awareness/ Preparation", and "Rebuilding/Growth") [44,45].

\section{Analysis}

Distribution characteristics were examined by means of item analysis (means, standard deviation, skewness, kurtosis, missing values) and Q-Q plots. The Q-Q plot is a graphical method for comparing two distributions. Subscale scores were plotted against a theoretical normal distribution (also called normal probability plot) where points should approximately form a straight line.

Reliability was examined by calculating internal consistency (Cronbach's alpha) including confidence intervals to increase precision of estimates [46], and by analysis of discriminability. Interpretation of Cronbach's alphas followed the recommendations of Nunnally [47] ("reliabilities of 0.7 or higher will suffice", p. 245) and George and Mallery [48] (acceptable: > .7; good: > .8; excellent: > .9). Discriminatory power was investigated by calculating the Corrected Item-Total Correlation (CITC) which gives the correlation between a given item and the sum score of the other items making up the scale. CITCs above .30 are considered adequate [49].

Furthermore, the continuous as well as the utility (categorised) CDMS total scores were analysed via Spearman correlations to establish relations among CDMS subscales, convergent validity (with two CDIS items), concurrent validity (with STORI recovery stage) and stability over one year.

\section{Results \\ Sample}

A total of 708 patients were screened for eligibility, of whom 588 were included. Reasons for exclusions were 
not meeting inclusion criteria $(\mathrm{n}=120)$, refusal to participate $(n=78)$, and other reasons $(n=3$ : one suicide, one deceased, one too anxious to participate). Patient participants are described in Table 1. Mean GAF score for participants indicates serious symptomatology and social disability, indicating that the TAG threshold had successfully resulted in a sample of participants who can be characterised as having severe mental illness.

Participating staff were in their mid-40s on average, and mean time of working in mental health services was 15 years. The "other" category for professions included nurse, district nurse, support time and recovery worker, and psychiatric trainee (see Table 2).

\section{Item characteristics and reliability Patient version}

As shown in Table 3 (left section), range of all items of the CDMS-P PD was quite homogenous $(S D=0.89-1.36)$. Items with the most extreme difficulties were \#4 and \#5,

Table 1 Sociodemographic and clinical characteristics of patient participants $(\mathrm{N}=\mathbf{5 8 8})$

\begin{tabular}{|c|c|}
\hline Study centre & \\
\hline Ulm, n (\%) & $112(19.05)$ \\
\hline London, $n(\%)$ & $85(14.46)$ \\
\hline Naples, $n$ (\%) & $101(17.18)$ \\
\hline Debrecen, $n$ (\%) & $97(16.49)$ \\
\hline Aalborg, $n(\%)$ & $98(16.67)$ \\
\hline Zurich, $n$ (\%) & 95 (16.16) \\
\hline Gender; female, $n$ (\%) & $307(52.21)$ \\
\hline Age; years, M (SD) & $41.69(10.74)$ \\
\hline Married; $n$ (\%) & $149(25.38)$ \\
\hline Ethnic group; Caucasian; $n$ (\%) & $552(94.04)$ \\
\hline Years in school; M (SD) & $10.43(1.88)$ \\
\hline Living alone; $n$ (\%) & $231(39.55)$ \\
\hline Paid or self employed; $n$ (\%) & $110(18.74)$ \\
\hline Receiving state benefits; $n$ (\%) & $425(72.40)$ \\
\hline Illness duration; years, M (SD) & $12.51(9.27)$ \\
\hline Diagnosis & \\
\hline Psychotic disorder, $n$ (\%) & $269(45.75)$ \\
\hline Mood disorder, $n$ (\%) & $200(34.01)$ \\
\hline Other, $n(\%)$ & $119(20.24)$ \\
\hline TAG; $M$ (SD) & $7.54(2.24)$ \\
\hline GAF; M (SD) & $49.03(10.96)$ \\
\hline STORI-30 & \\
\hline (1) Moratorium, $n$ (\%) & $115(19.79)$ \\
\hline (2) Awareness and Preparation, $n$ (\%) & $145(24.96)$ \\
\hline (3) Rebuilding and Growth, $n$ (\%) & $321(55.25)$ \\
\hline
\end{tabular}

Notes: Missing values: $\mathrm{N}=1$ (married, ethnic group, work, benefits), $\mathrm{N}=4$ (living), $\mathrm{N}=7$ (STORI), $\mathrm{N}=11$ (school), $\mathrm{N}=29$ (GAF).
Table 2 Sociodemographic and professional characteristics of staff participants $(\mathrm{N}=\mathbf{2 1 3})$

\begin{tabular}{lr}
\hline Study centre & \\
Ulm, $n$ (\%) & $48(22.54)$ \\
London, $n$ (\%) & $38(17.84)$ \\
Naples, $n$ (\%) & $17(7.98)$ \\
Debrecen, $n$ (\%) & $8(3.79)$ \\
Aalborg, $n$ (\%) & $59(27.69)$ \\
Zurich, $n$ (\%) & $43(20.19)$ \\
Gender; female, $n$ (\%) & $128(61.84)$ \\
Age; years, $M$ (SD) & $46.03(10.47)$ \\
Profession & \\
$\quad$ Psychiatrist, $n$ (\%) & $75(36.41)$ \\
$\quad$ Psychologist, $n$ (\%) & $19(9.22)$ \\
$\quad$ Social Worker, $n$ (\%) & $11(5.34)$ \\
Other, $n$ (\%) & $101(49.03)$ \\
Working in outpatient mental health services; years, $M$ (SD) & $9.41(8.44)$ \\
Working in mental health services; years, M (SD) & $14.99(9.66)$ \\
Number of patients in study; $M$ (SD) & $2.76(4.46)$ \\
\hline
\end{tabular}

Notes. Missing values: $\mathrm{N}=6$ (gender), $\mathrm{N}=7$ (profession), $\mathrm{N}=54$ (working outpatient), $\mathrm{N}=41$ (working mental health).

indicating that participants used $32.7 \%(2.61-0.97 / 5)$ of the whole range of the 5-point scale. Skewness of items averaged at 0.14 $(S D=0.37$; range $=-0.51[\# 4]-1.05[\# 5])$, and kurtosis at $-0.48(S D=0.64 ;$ range $=-1.29[\# 1]-0.81$ [\#7]), respectively. Number of missing values ranged from $0.17-1.87 \%$. Mean discriminative power (corrected item-total correlation) was $0.48(\mathrm{SD}=0.13)$, with item \#4 falling below the cut-off of 0.3. Cronbach's $\alpha$ ranged between .87 and .89 regardless of the omission of any item.

For the CDMS-P IN, participants used 15.5\% of the scale range. Skewness was negative for all items $(\mathrm{M}=-1.35$; $\mathrm{SD}=0.29$; range $=-0.82[\# 19]--1.56[\# 18]$; kurtosis: $\mathrm{M}=2.00 ; \mathrm{SD}=1.47$; range $=-0.35[\# 19]-3.50[\# 18]$ ), and missing values ranged from $0.17-0.34 \%$. Cronbach's $\alpha$ substantially increased when deleting item \#19 which also showed low CTIC, so this item is deleted from the sub-scale in subsequent analysis.

\section{Staff version}

As also shown in Table 3 (right section), range of all items of the CDMS-S PD was also quite homogenous $(S D=0.55-1.27)$. Items with the most extreme difficulties were $\# 1$ and $\# 5$, indicating that participants used $31.6 \%$ of the 5-point range. Mean skewness of items was -0.10 $(\mathrm{SD}=0.50$; range $=-0.81[\# 1]-1.13[\# 5])$, and mean kurtosis was $0.42(\mathrm{SD}=1.45$; range $=-0.92[\# 2]-3.38$ [\#7]). Number of missing values ranged from $0-1.58 \%$, and mean discriminative power was $0.57(\mathrm{SD}=0.16)$, with 
Table 3 Item characteristics CDMS Patient $(N=588)$ and Staff $(N=570)$ versions

\begin{tabular}{|c|c|c|c|c|c|c|}
\hline \multirow[b]{2}{*}{ Participation in Decision Making (PD) sub-scale } & \multicolumn{3}{|c|}{ Patient version } & \multicolumn{3}{|c|}{ Staff version } \\
\hline & Mean (SD) & CITC & $a$ & Mean (SD) & CITC & $a$ \\
\hline 1 Important decisions. $^{a}$ & $1.95(1.36)$ & 0.524 & 0.837 & $2.71(1.27)$ & 0.767 & 0.870 \\
\hline 2 Comply with clinician's advice. ${ }^{a}$ & $1.58(1.18)$ & 0.520 & 0.837 & $2.20(1.19)$ & 0.668 & 0.876 \\
\hline 3 Treatment in the clinic. ${ }^{a}$ & $1.85(1.34)$ & 0.552 & 0.835 & $2.58(1.22)$ & 0.695 & 0.874 \\
\hline 4 Every day problems. & $2.61(1.08)$ & 0.140 & 0.857 & $2.38(1.10)$ & 0.302 & 0.894 \\
\hline 5 More control when worsening. ${ }^{a}$ & $0.97(0.98)$ & 0.445 & 0.842 & $1.13(0.94)$ & 0.453 & 0.885 \\
\hline 6 See clinician how often. & $2.00(1.23)$ & 0.413 & 0.844 & $1.39(0.96)$ & 0.341 & 0.890 \\
\hline 7 Return to work. & $2.24(0.89)$ & 0.453 & 0.842 & $1.95(0.60)$ & 0.545 & 0.882 \\
\hline 8 Suitable occupation. & $2.46(0.91)$ & 0.368 & 0.845 & $1.92(0.55)$ & 0.325 & 0.888 \\
\hline 9 Amount of work. & $2.42(0.97)$ & 0.405 & 0.844 & $2.04(0.63)$ & 0.508 & 0.883 \\
\hline 10 See a doctor. & $2.40(1.29)$ & 0.393 & 0.845 & $2.17(0.95)$ & 0.485 & 0.884 \\
\hline 11Dosage of medication. & $1.35(1.06)$ & 0.573 & 0.835 & $2.66(0.73)$ & 0.697 & 0.876 \\
\hline 12 Another medication. & $1.28(1.02)$ & 0.612 & 0.833 & $2.68(0.77)$ & 0.701 & 0.876 \\
\hline 13 Medication at all. & $1.53(1.20)$ & 0.617 & 0.831 & $2.60(0.76)$ & 0.741 & 0.874 \\
\hline 14 Form of medication. & $1.83(1.26)$ & 0.555 & 0.835 & $2.18(0.78)$ & 0.563 & 0.881 \\
\hline 15 Duration of medication. & $1.24(1.04)$ & 0.663 & 0.830 & $2.70(0.78)$ & 0.737 & 0.874 \\
\hline Information (IN) sub-scale & Mean (SD) & CITC & $a$ & Mean (SD) & CITC & $a$ \\
\hline 16 Informed about the facts. & $3.14(0.94)$ & 0.506 & 0.660 & $2.63(0.89)$ & 0.350 & 0.717 \\
\hline 17 Know exactly. & $3.29(0.86)$ & 0.617 & 0.630 & $3.04(0.74)$ & 0.638 & 0.631 \\
\hline 18 Explain purpose. & $3.41(0.74)$ & 0.623 & 0.639 & $3.43(0.63)$ & 0.550 & 0.665 \\
\hline 19 Information when asked for. ${ }^{a}$ & $2.64(1.23)$ & 0.121 & 0.807 & $3.03(0.91)$ & 0.232 & 0.753 \\
\hline 20 Side effects. & $3.23(0.97)$ & 0.467 & 0.672 & $2.55(0.97)$ & 0.516 & 0.664 \\
\hline 21 Various treatment methods. & $3.39(0.80)$ & 0.587 & 0.643 & $3.25(0.70)$ & 0.565 & 0.656 \\
\hline
\end{tabular}

Notes: ${ }^{\text {a }} 5$ items reverse coded for analysis; CITC: Corrected Item-Total Correlation; $a=a$ after item deletion; Ns for CITC and a: 573 for PD-P, 583 for IN-P, 555 for PD-S, and 568 for IN-S.

some items $(\# 4, \# 8)$ barely meeting the cut-off of adequate discriminability. Consistent with the patient version, Cronbach's $\alpha$ ranged between .87 and .89 regardless of the omission of any item.

For the CDMS-S IN, participants used $17.5 \%$ of the scale range, and skewness was negative for all items $(\mathrm{M}=-0.74 ; \mathrm{SD}=0.33$; range $=-1.09$ [\#19] --0.23 [\#20]; kurtosis: $\mathrm{M}=0.86 ; \mathrm{SD}=1.04$; range $=-0.70[\# 20]-1.89[\# 18])$, and missing values ranged from $0-0.35 \%$. Furthermore, as in the patient version, Cronbach's $\alpha$ was highest when deleting item \#19 which also showed poor CITC, so this item is deleted from the sub-scale in subsequent analysis.

Descriptives of all four CDMS subscale scores without item \#19 in both patient and staff versions as well as Cronbach's $\alpha$ 's including their confidence intervals are shown in the upper part of Table 4 . As can be seen in Figure 1,0 for both patient and staff versions, PD scores are approximately normally distributed which is not the case for IN scores which are distinctly skewed to the left.

As also shown in Table 4, clinical utility categorical scores show that the vast majority of both patients and staff members prefer shared (rather than passive or active) participation in decision making, while need for information was mostly high in patients and predominantly moderate in staff.

\section{Stability}

Descriptives for CDMS subscales at one-year follow-up are also shown in Table 4. Distribution of clinical utility categorical scores was similar to baseline data. Paired t-tests showed that, compared to T0, scores one year later were higher for IN staff $\left(\mathrm{t}_{\mathrm{df}=489}=-2.59, \mathrm{p}=.010\right)$, and not different for the other scales (PD patient: $t_{d f=511}=-1.93, p=.054$; IN patient: $\mathrm{t}_{\mathrm{df}=513}=-0.21, \mathrm{p}=.830$; PD staff: $\left.\mathrm{t}_{\mathrm{df}=489}=0.26, \mathrm{p}=.798\right)$. Spearman correlation coefficients between baseline and one-year follow-up of the four scales ranged between 0.36 and 0.79 (and 0.24 and 0.66 for the clinical utility categorical scores), and were higher for the PD scales in than for the IN scales in both patient and staff versions.

\section{Validity}

Spearman correlations between PD and IN subscales were close to 0 for both patients and staff versions (see Table 5). 
Table 4 CDMS subscale scores at baseline and follow-up

\begin{tabular}{|c|c|c|c|c|c|c|c|c|}
\hline & Scale & Mean (SD) & $N$ & $a(\mathrm{Cl} 95 \%)$ & Utility: & passive, $N(\%)$ & shared, $N(\%)$ & active, $N(\%)$ \\
\hline \multirow[t]{6}{*}{ Baseline } & PD Patient & $1.84(0.64)$ & 586 & $0.849(0.830-0.866)$ & & $175(29.86)$ & $319(54.44)$ & $92(15.69)$ \\
\hline & PD Staff & $1.83(0.57)$ & 563 & $0.888(0.874-0.901)$ & & $124(22.02)$ & $397(70.51)$ & $42(7.46)$ \\
\hline & & & & & Utility: & low, $N(\%)$ & moderate, $N$ (\%) & high, $N(\%)$ \\
\hline & IN Patient & $3.29(0.65)$ & 587 & $0.808(0.782-0.831)$ & & $21(3.58)$ & $207(35.26)$ & $359(61.16)$ \\
\hline & IN Staff & $2.98(0.56)$ & 570 & $0.753(0.720-0.784)$ & & $45(7.89)$ & $324(56.84)$ & $201(35.26)$ \\
\hline & Scale & Mean (SD) & $N$ & $\rho_{t t}$ & Utility: & passive, $N$ (\%) & shared, $N(\%)$ & active, $N(\%)$ \\
\hline \multirow[t]{9}{*}{1 year } & PD Patient & $1.87(0.68)$ & 514 & $\rho=0.69 ; p<0.001 ; N=512$ & & $152(29.57)$ & $276(53.69)$ & $86(16.73)$ \\
\hline & & & & Utility*: $\rho=0.64 ; p<0.001$ & & & & \\
\hline & PD Staff & $1.84(0.57)$ & 491 & $\rho=0.79 ; p<0.001 ; N=485$ & & $114(23.22)$ & $337(68.64)$ & $40(8.15)$ \\
\hline & & & & Utility*: $\rho=0.66 ; p<0.001$ & & & & \\
\hline & & & & & Utility: & low, $N(\%)$ & moderate, $N(\%)$ & high, $N(\%)$ \\
\hline & IN Patient & $3.31(0.55)$ & 515 & $\rho=0.36 ; p<.001 ; N=514$ & & $12(2.33)$ & $213(41.36)$ & $290(56.31)$ \\
\hline & & & & Utility $^{*}: \rho=0.24 ; p<0.001$ & & & & \\
\hline & IN Staff & $3.05(0.57)$ & 495 & $\rho=0.44 ; p<0.001 ; N=490$ & & $27(5.45)$ & $270(54.55)$ & $198(40.00)$ \\
\hline & & & & Utility*: $\rho=0.31 ; p<.001$ & & & & \\
\hline
\end{tabular}

Notes: $\mathrm{Cl}=$ confidence interval; Utility: Clinical utility categorical data; ${ }^{*}=\mathrm{Ns}$ as previous line.

As also shown in Table 5, correlations were moderate for PD with the CDIS involvement item in both patients and staff. Correlation of IN with the CDIS information item was also moderate in patients, but the two variables were hardly related in the staff version. Finally, analysis of concurrent validity showed that CDMS-P PD was unrelated to recovery, while CDMS-P IN scores increased with a higher STORI stage $\left(\mathrm{F}_{\mathrm{df}}=2 ; 577=3.54 ; \mathrm{p}=.030\right.$; also see Table 4). Correlations using the clinical utility categorical scores yielded similar results.

\section{Discussion}

This paper reports on instrument development and psychometric properties of the Clinical Decision Making Style Scale (CDMS) which consists of patient (CDMS-P) and staff (CDMS-S) versions which are structured identically with wording changed to reflect the different perspectives.

Instrument development followed current state-of-theart recommendations to ensure consistently high standards across study sites in preparing the source version

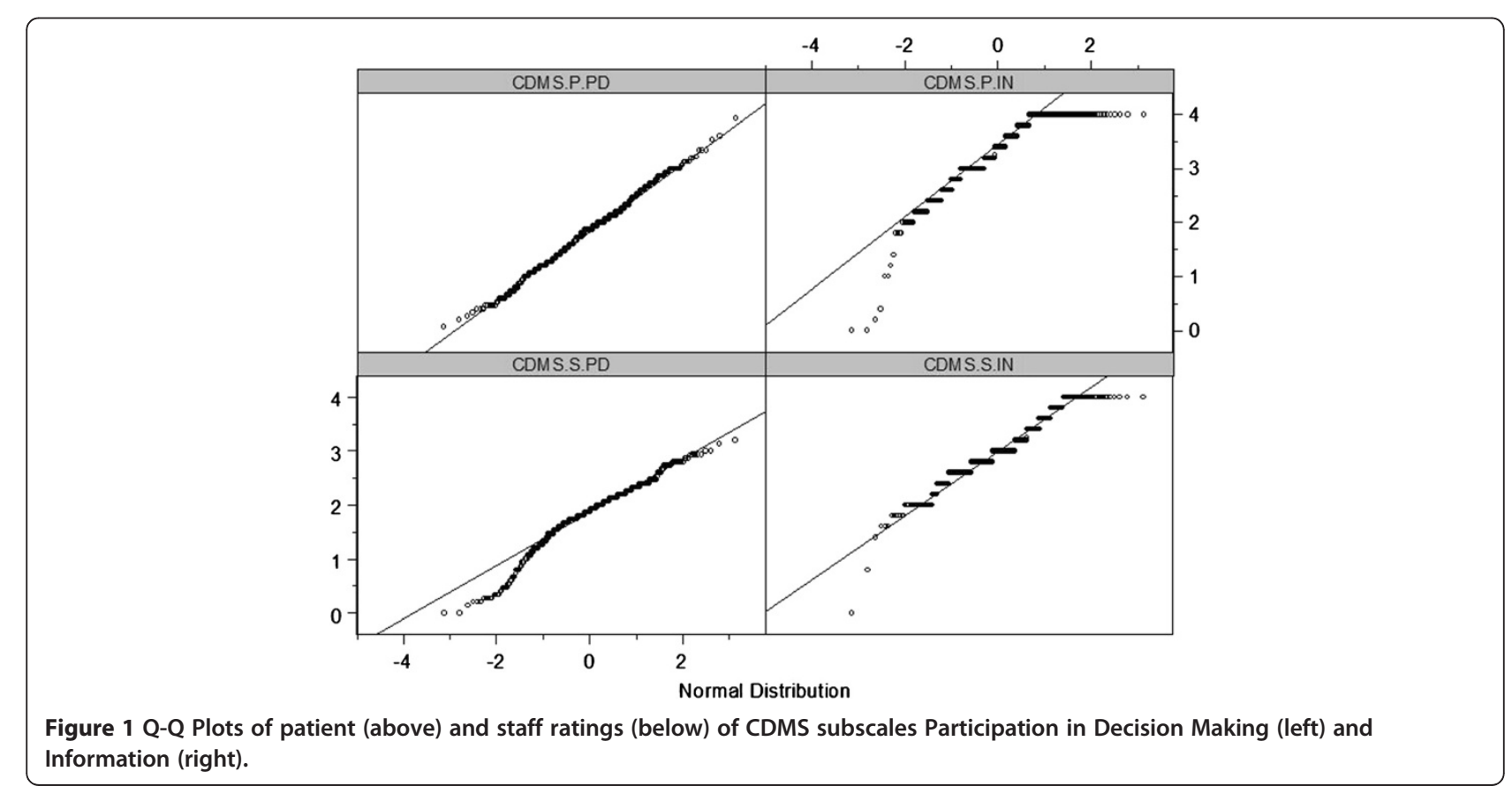


Table 5 Relations among CDMS subscales and convergent validity (Spearman)

\begin{tabular}{|c|c|c|c|c|}
\hline Scale & IN & CDIS involvement & CDIS information & STORI \\
\hline \multicolumn{5}{|c|}{ Continuous } \\
\hline \multirow[t]{3}{*}{ PD Patient } & $\rho=0.01$ & $\rho=-0.27$ & & $\rho=0.04$ \\
\hline & $p=0.837$ & $p<0.001$ & & $p=0.319$ \\
\hline & $N=586$ & $N=445$ & & $N=580$ \\
\hline \multirow[t]{3}{*}{ PD Staff } & $\rho=0.14$ & $\rho=-0.43$ & & \\
\hline & $p=0.001$ & $p<0.001$ & & \\
\hline & $N=563$ & $N=417$ & & \\
\hline \multirow[t]{3}{*}{ IN Patient } & & & $\rho=0.31$ & $\rho=0.12$ \\
\hline & & & $p<.001$ & $p=.003$ \\
\hline & & & $N=446$ & $N=580$ \\
\hline \multirow[t]{3}{*}{ IN Staff } & & & $\rho=0.27$ & \\
\hline & & & $p<0.001$ & \\
\hline & & & $N=422$ & \\
\hline \multicolumn{5}{|l|}{ Utility* } \\
\hline \multirow[t]{2}{*}{ PD Patient } & $\rho=0.06$ & $\rho=-0.26$ & & $\rho=0.07$ \\
\hline & $p=0.181$ & $p<0.001$ & & $p=0.093$ \\
\hline \multirow[t]{2}{*}{ PD Staff } & $\rho=0.08$ & $\rho=-0.39$ & & \\
\hline & $p=0.051$ & $p<0.001$ & & \\
\hline \multirow[t]{2}{*}{ IN Patient } & & & $\rho=0.26$ & $\rho=0.11$ \\
\hline & & & $p<0.001$ & $p=0.008$ \\
\hline \multirow[t]{2}{*}{ IN Staff } & & & $\rho=0.18$ & \\
\hline & & & $p<0.001$ & \\
\hline
\end{tabular}

Notes: ${ }^{*} \mathrm{Ns}$ as above.

and the final versions in five languages. Throughout this process, special efforts were made to use a participatory approach, i.e. expert advice from patients and staff was systematically sought from the start, in order to generate an instrument which is feasible and meaningful to its users. High face validity and completion rates of no less than $98 \%$ on any CDMS item indicate that this process has been successful.

Item analysis showed that items of the PD subscale were approximately normally distributed and that participants used a large portion of the 5-point scale. In contrast, the items in the IN subscale were distinctly left skewed and consequently also participants' use of the scale range was rather restricted. Item-level findings were consistent with the total scores, which for the PD subscale in both patients and staff showed approximate normal distribution, while both IN subscale totals were distinctly left skewed. This pattern is in line with Giersdorf and colleagues [50] who also reported that IN items showed little variance and a ceiling effect in 646 people with different chronic conditions. In line with Ende and colleagues [28], this indicates that patients have a strong interest in being well informed. Additionally it shows that mental health professionals acknowledge a high need for information among service users.

Furthermore, categorising the subscale totals according to clinical utility criteria showed that both patients and staff members preferred shared (rather than passive or active) participation in decision making, while need for information was high from the patient perspective and moderate from the staff perspective.

\section{Reliability}

Reliability indices were satisfactory to excellent for all items in the PD subscale. This was also the case in both patient and staff versions of the IN subscale, apart from one item (\#19) which showed low discriminatory power and contributed negatively to internal consistency in both patient and staff versions of the IN subscale. After deletion of this item, internal consistency (Cronbach's $\alpha$ 's) including the lower bounds of the 95\% confidence intervals were at least adequate, and mainly good. These findings are in line with previous research on the API which has also identified some items with poor reliability [33] and reported similarly good internal consistency $[28,32]$ in people with various conditions. However, in a study with people with schizophrenia [29], the API's internal consistency was $\operatorname{poor}(\alpha=0.57)$, justifying the efforts made during the CDMS development process to modify and maximise its meaningfulness for people with severe mental illness.

Stability over one year was high for PD in both patients and staff, and moderate for IN. Overall, this finding shows that, as intended, the CDMS measures a relatively constant trait-like component of clinical decision making.

\section{Validity}

PD and IN subscales did not correlate. This indicates convergent validity and shows that, as in the original API, preferences for participation in decision making are independent of preferences for information. This study adds that this is also the case in people with severe mental illness and in mental health professionals. Furthermore, convergent validity could be established for the PD subscale for both patient and staff versions, and for the IN subscale for the patient version. However, correlations with the corresponding CDIS items were only moderate, and the IN subscale did not correlate with the corresponding CDIS information item. When interpreting these finding on convergent validity, it should be borne in mind that CDMS taps into general aspects of decision making style, while CDIS rates involvement and information relating to a specific decision making encounter. Finally, concurrent validity was demonstrated for the CDMS-P IN by showing that the patient-rated need for information increased with a higher stage of 
recovery, while the CDMS-P PD subscale was not related to recovery. Thus, concurrent validity could only partially be demonstrated. This finding raises the question about the relationship between recovery and participation in decision making.

Analysis on all indices of reliability and validity for the categorised clinical utility categories yielded results similar to the analysis of the continuous CDMS variables. This finding indicates the adequacy of the chosen cut-off points.

\section{Limitations}

This study has several limitations. First, test-retest reliability in the strict sense, with participants filling in the scale again shortly after initial completion has not been examined. Test-retest reliability should be tested for shorter intervals. Second, evaluation of validity was made difficult because clinical decision-making style is a specific concept, making identification of comparator scales problematic. Third, there are weaknesses in sample generalizability. In the instrument development, convenience samples were chosen as participants of the focus group. Thus, the samples may not truly reflect the mentally ill population. The same issue arises for staff participants in focus groups. Fourth, a pilot phase between instrument development and administration of the instruments in the CEDAR study would have been worthwhile. Finally, future studies might consider sampling other populations containing native speakers of the five languages.

\section{Conclusion}

This study investigated the psychometric properties of the Clinical Decision Making Style (CDMS) scale which measures general and specific preferences for decision making (subscale Participation in Decision Making - PD) as well as preferences regarding the provision of information to the patient (subscale Information - IN) from the perspectives of people with severe mental illness (CDMS $-\mathrm{P}$ ) and mental health professionals (CDMS $-\mathrm{S}$ ). The subscales reliably measured distinct characteristics of decision making, which showed relative stability over time. Validity was demonstrated to some extent and needs further investigation. Overall, the psychometric properties of the CDMS are satisfactory making it possible to further examine the relation between clinical decision making and outcome in the treatment of people with severe mental illness across Europe.

\section{Abbreviations}

CDMS: Clinical Decision Making Style Scale; CDMS-P: Clinical Decision Making Style Scale Patient Version; CDMS-P: Clinical Decision Making Style Scale Staff Version; PD: Participation in Decision Making (CDMS subscale);

IN: Information (CDMS subscale); API: Autonomy Preference Index.
Competing interests

The authors declare that they have no competing interests.

\section{Authors' contributions}

PN, SL and BP coordinated instrument development across sites. PN, HJ, DG, $\mathrm{TI}, \mathrm{MKB}, \mathrm{HOS}$, and $\mathrm{AB}$ collected data for instrument development and for the main study. PN, SL and KA analysed the qualitative data from instrument development. BP drafted the manuscript and carried out the quantitative data analysis to establish psychometric properties. PN, MS, AF, AE, and WK revised the manuscript critically for important intellectual content. All authors have given final approval of the version to be published.

\section{Acknowledgements}

The CEDAR study is funded by a grant from the European Union' Seventh Framework Programme (Programme Acronym: FP7-HEALTH; Subprogramme area: Improving clinical decision making; Project Reference: 223290).

The CEDAR study group.

The study "Clinical decision making and outcome in routine care for people with severe mental illness" (CEDAR) is a multicentre collaboration between the Department of Psychiatry II at Ulm University, Germany (Bernd Puschner); the Section for Recovery at Institute of Psychiatry, London, U.K. (Mike Slade); the Department of Psychiatry at Second University of Naples, Italy (Mario Maj); the Department of Psychiatry at University of Debrecen Medical and Health Science Center, Hungary (Anikó Égerházi); the Unit for Psychiatric Research at Aalborg University Hospital and Aarhus University Hospital, Denmark (Povl Munk-Jørgensen); and the Department of General and Social Psychiatry at University of Zurich, Switzerland (Wulf Rössler).

The CEDAR study group includes the following members: Bernd Puschner (chief investigator), Katrin Arnold, Esra Ay, Thomas Becker, Jana Konrad, Petra Neumann, Sabine Steffen, Nadja Zentner (Ulm); Mike Slade, Elly Clarke, Harriet Jordan (London); Mario Maj, Andrea Fiorillo, Domenico Giacco, Mario Luciano, Corrado De Rosa, Gaia Sampogna, Valeria Del Vecchio, Pasquale Cozzolino, Heide Gret Del Vecchio, Antonio Salzano (Naples); Anikó Égerházi, Tibor Ivánka, Marietta Nagy, Roland Berecz, Teodóra Glaub, Ágnes Süveges, Attila Kovacs, Erzsebet Magyar (Debrecen ); Povl Munk-Jørgensen, Malene Krogsgaard Bording, Helle Østermark Sørensen, Jens-Ivar Larsen (Aalborg); Wolfram Kawohl, Arlette Bär, Wulf Rössler, Susanne Krömer, Jochen Mutschler, Caitriona Obermann (Zurich).

\section{Author details}

${ }^{1}$ Department of Psychiatry II, UIm University, Ludwig-Heilmeyer-Str. 2, Günzburg 89312, Germany. ${ }^{2}$ King's College London, Section for Recovery, Institute of Psychiatry, London, U.K. ${ }^{3}$ Department of Psychiatry, Second University of Naples, Naples, Italy. ${ }^{4}$ Department of Psychiatry, University of Debrecen Medical and Health Science Center, Debrecen, Hungary. ${ }^{5}$ Unit for Psychiatric Research, Aalborg Psychiatric Hospital, Aalborg University Hospital, Aalborg, Denmark. ${ }^{6}$ Department of General and Social Psychiatry, University of Zurich, Zurich, Switzerland.

Received: 25 July 2012 Accepted: 29 January 2013

Published: 4 February 2013

\section{References}

1. Charles C, Gafni A, Whelan T: Shared decision-making in the medical encounter: what does it mean? (or it takes at least two to tango). Soc Sci Med 1997, 44:681-692.

2. Coulter A: The autonomous patient: ending paternalism in medical care. London: The Nuffield Trust, TSO; 2003.

3. President's Commission for the Study of Ethical Problems in Medicine and Biomedical and Behavioral Research: Making health care decisions: a report on the ethical and legal implications of informed consent in the patientpractitioner relationship. Washington, D.C: US Government Printing Office; 1982.

4. Brar SS, Stone GW: Decision-making: stenting in acute myocardial infarction. Future Cardiol 2010, 6:301-314.

5. Cunningham VL: The outcome wheel: a potential tool for shared decision-making in ischemic stroke thrombolysis. CJEM 2008, 10:545-551.

6. Sajid S, Mohile SG, Szmulewitz R, Posadas E, Dale W: Individualized decision-making for older men with prostate cancer: balancing cancer control with treatment consequences across the clinical spectrum. Semin Oncol 2011, 38:309-325. 
7. Tariman JD, Berry DL, Cochrane B, Doorenbos A, Schepp K: Preferred and actual participation roles during health care decision making in persons with cancer: a systematic review. Ann Oncol 2010, 21:1145-1151.

8. O'Brien MA, Whelan TJ, Charles C, Ellis PM, Gafni A, Lovrics P, Hasler A, Dimitry S: Women's perceptions of their treatment decision-making about breast cancer treatment. Patient Educ Couns 2008, 73:431-436.

9. Waljee JF, Rogers MA, Alderman AK: Decision aids and breast cancer: do they influence choice for surgery and knowledge of treatment options? J Clin Oncol 2007, 25:1067-1073.

10. Bieber C, Muller KG, Blumenstiel K, Hochlehnert A, Wilke S, Hartmann M, Eich W: A shared decision-making communication training program for physicians treating fibromyalgia patients: effects of a randomized controlled trial. J Psychosom Res 2008, 64:13-20.

11. Drake RE, Deegan PE: Shared decision making is an ethical imperative. Psychiatr Serv 2009, 60:1007.

12. National Collaborating Centre for Mental Health: Schizophrenia: core interventions in the treatment and management of schizophrenia in adults in primary and secondary care. London: The British Psychological Society and The Royal College of Psychiatrists; 2009.

13. Duncan E, Best $C$, Hagen S: Shared decision making interventions for people with mental health conditions. Cochrane Database Syst Rev 2010, (1):CD007297. doi:10.1002/14651858.CD007297.pub2.

14. Watt S: Clinical decision-making in the context of chronic illness. Health Expect 2000, 3:6

15. Wills CE, Holmes-Rovner M: Integrating decision making and mental health interventions research: research directions. Clin Psychol Sci Pract 2006, 13:9-25.

16. Puschner B, Steffen S, Slade M, Kaliniecka H, Maj M, Fiorillo A, MunkJorgensen P, Larsen Jl, Egerhazi A, Nemes Z, et al: Clinical decision making and outcome in routine care for people with severe mental illness (CEDAR): study protocol. BMC Psychiatry 2010, 10:90

17. Simon D, Loh A, Harter M: Measuring (shared) decision-making-a review of psychometric instruments. Z Arztl Fortbild Qualitatssich 2007, 101:259-267.

18. Dy SM: Instruments for Evaluating Shared Medical Decision Making. Med Care Res Rev 2007, 64:623-649.

19. Scholl I, Loon MK, Sepucha K, Elwyn G, Legare F, Härter M, Dirmaier J: Measurement of shared decision making - a review of instruments. Z Evid Fortbild Qual Gesundhwes 2011, 105:313-324.

20. Legare F, Moher D, Elwyn G, Leblanc A, Gravel K: Instruments to assess the perception of physicians in the decision-making process of specific clinical encounters: a systematic review. BMC Med Inform Decis Mak 2007, 7:30.

21. Elwyn G, Edwards A, Kinnersley P, Grol R: Shared decision making and the concept of equipoise: the competences of involving patients in healthcare choices. Br J Gen Pract 2000, 50:892-899.

22. Towle A, Godolphin W: Framework for teaching and learning informed shared decision making. BMJ 1999, 319:766-771.

23. Coulter A: Partnerships with patients: the pros and cons of shared clinical decision making. J Health Serv Res Pol 1997, 2:112-121.

24. Wills CE, Holmes-Rovner M: Preliminary validation of the Satisfaction With Decision scale with depressed primary care patients. Health Expect 2003, 6:149-159.

25. Simon D, Schorr G, Wirtz M, Vodermaier A, Caspari C, Neuner B, Spies C, Krones $\mathrm{T}$, Keller $\mathrm{H}$, Edwards $\mathrm{A}$, et al: Development and first validation of the shared decision-making questionnaire (SDM-Q). Patient Educ Couns 2006, 63:319-327.

26. Decision Self-Efficacy Scale. http://decisionaid.ohri.ca/eval_self.html.

27. Bunn $\mathrm{H}, \mathrm{O}^{\prime}$ Connor $\mathrm{A}$ : Validation of client decision-making instruments in the context of psychiatry. Can J Nurs Res 1996, 28:13-27.

28. Ende J, Kazis L, Ash A, Moskowitz MA: Measuring patients' desire for autonomy: decision making and information-seeking preferences among medical patients. J Gen Intern Med 1989, 4:23-30.

29. Hamann J, Cohen R, Leucht S, Busch R, Kissling W: Do patients with schizophrenia wish to be involved in decisions about their medical treatment? Am J Psychiatry 2005, 162:2382-2384.

30. Hamann J, Mendel R, Schebitz M, Reiter S, Buhner M, Cohen R, Berthele A, Kissling W: Can psychiatrists and neurologists predict their patients' participation preferences? J Nerv Ment Dis 2010, 198:309-311.

31. Hamann J, Bieber C, Elwyn G, Wartner E, Horlein E, Kissling W, Toegel C, Berth $H$, Linde $K$, Schneider A: How do patients from eastern and western Germany compare with regard to their preferences for shared decision making? Eur J Public Health 2011, online first.
32. Hamann J, Neuner B, Kasper J, Vodermaier A, Loh A, Deinzer A, Heesen C, Kissling W, Busch R, Schmieder R, et al: Participation preferences of patients with acute and chronic conditions. Health Expect 2007, 10:358-363.

33. Simon D, Kriston L, Loh A, Spies C, Scheibler F, Wills C, Harter M: Confirmatory factor analysis and recommendations for improvement of the Autonomy-Preference-Index (API). Health Expect 2010, 13:234-243.

34. Slade M, Jordan H, Clarke E, Arnold K, Fiorillo A, Giacco D, Egerhazi A, Nagy $M$, Krogsgaard Bording M, Ostermark Sørensen $H$, et al: The development and evaluation of a five-language multi-perspective standardised measure: Clinical Decision-making Involvement and Satisfaction (CDIS). 2013, In submission.

35. Konrad J, Loos S, Slade M, Jordan H, Giacco D, De Rosa C, Egerhazi A, Nagy M, Krogsgaard Bording M, Ostermark Sørensen $H$, et al: A five-language multiperspective instrument to assess clinical decision making in the routine care of people with severe mental illness. 2013, In submission.

36. Wild D, Grove A, Martin M, Eremenco S, McElroy S, Verjee-Lorenz A, Erikson $P$ : Principles of good practice for the translation and cultural adaptation process for patient-reported outcomes (PRO) measures: report of the ISPOR Task Force for Translation and Cultural Adaptation. Value Health 2005, 8:94-104.

37. Barbour R, Kitzinger J: Developing focus group research: politics, theory and practice. London: Sage; 1999.

38. Kitzinger J: Qualitative research. Introducing focus groups. Br Med J 1995 311:299-302.

39. Krueger RA, Casey MA, Focus Groups: A Practical Guide for Applied Research London: Sage; 2008.

40. Loos S, Neumann P, Arnold K, Slade M, Fiorillo A, Frøkjær Krogsgaard Bording M, Ivanka T, Kawohl W, Puschner B: Gemeinsame Entscheidungsfindung in der Behandlung von Patienten mit schweren psychischen Erkrankungen: Eine Fokusgruppen-Untersuchung [Shared decision-making in the treatment of people with severe mental illness: a focus group study]. Psychiatrische Praxis 2013, 40:23-29.

41. First MB, Spitzer RL, Gibbon M, Williams JBW: Structured Clinical Interviews for DSM-IV Axis I Disorders - Clinical Version (SCID-CV). Washington, DC: American Psychiatric Press; 1997

42. Möller HJ, Jäger M, Riedel M, Obermeier M, Strauss A, Bottlender R: The Munich 15-year follow-up study (MUFSSAD) on first-hospitalized patients with schizophrenic or affective disorders: assessing courses, types and time stability of diagnostic classification. Eur Psychiatr 2010, 26:231-243.

43. Slade M, Cahill S, Kelsey W, Leese M, Powell R, Strathdee: Threshold 4: an evaluation of the Threshold Assessment Grid as an aid to mental health referrals. Primary Care Mental Health 2003, 1:45-54

44. Andresen R, Caputi P, Oades L: Stages of recovery instrument: development of a measure of recovery from serious mental illness. Aust N Z J Psychiatry 2006, 40:972-980

45. Weeks G, Slade M, Hayward M: A UK validation of the Stages of Recovery Instrument. Int J Soc Psychiatry 2011, 57:446-454.

46. lacobucci $D$, Duhachek $A$ : Advancing alpha: measuring reliability with confidence. J Consumer Psychol 2003, 13:478-487.

47. Nunnally JC: Psychometric theory. New York: McGraw-Hill; 1978

48. George D, Mallery P: SPSS for Windows step by step: A simple guide and reference. Boston: Allyn \& Bacon; 2012.

49. De Vaus D: Surveys in social research. London: Routledge; 2002

50. Giersdorf N, Loh A, Bieber C, Caspari C, Deinzer A, Doering T, Eich W, Hamann J, Heesen C, Kasper J, et al: Entwicklung eines Fragebogens zur Partizipativen Entscheidungsfindung [Development and validation of assessment instruments for shared decision making] Bundesgesundheitsblatt Gesundheitsforschung Gesundheitsschutz 2004, 47:969-976

\section{doi:10.1186/1471-244X-13-48}

Cite this article as: Puschner et al:: Development and psychometric properties of a five-language multiperspective instrument to assess clinical decision making style in the treatment of people with severe mental illness (CDMS). BMC Psychiatry 2013 13:48. 